\title{
Exploring IT-Enabled Public Sector Innovation in U.S. States
}

\author{
James S. Denford \\ Management \& Economics Department \\ Royal Military College of Canada \\ Jim.Denford@rmc.ca
}

\author{
Gregory S. Dawson \\ W.P. Carey School of Business \\ Arizona State University \\ GregorySDawson@gmail.com
}

\author{
Kevin C. Desouza \\ School of Public Affairs \\ Arizona State University \\ Kevin.Desouza@asu.edu
}

\begin{abstract}
Scholars and practitioners often assume that the public sector mirrors the private sector and that it is possible to merely port strategies between domains. However, we highlight the substantial differences between the domains and explore how IT-enabled innovation shapes and is shaped within state government. Analyzing state-level IT governance data using crisp-set Qualitative Comparative Analysis, we uncover that low state attainment is a catalyst for IT-enabled innovation. We uncover and differentiate several types of innovations and also find that successful innovation requires the collaboration of the legislature, governor and CIO.
\end{abstract}

\section{Introduction}

State-level innovation adoption in the U.S. is uneven, ranging from states who have provided fully transparent and open access to state information to citizens [1] to states whose systems are "broken" and cannot provide even basic information such as on spending for major spending initiatives [2]. For example, Oklahoma has been on the forefront of innovative transparency movement in the states by implementing Oklahoma OpenBooks, which is publically available website with detailed and searchable information on state revenue and spending [1]. Minnesota and North Dakota have followed a similar path to transparency innovation by providing open and searchable access to their ERP systems [1]. On the other hand, other states continue to struggle with even basic technology usage. For example, the governor of North Carolina recently described the state's computer systems as "broken" and the state auditor reported that the state's computer systems are unable to provide even basic information on spending for major spending initiatives including Medicaid and food stamps [2].
Despite the importance of innovation to the public sector, the extant literature has primarily focused on private sector innovation and IT governance to the relative exclusion of study on innovation and governance in the public sector. Because of this lack of scholarship, little is known about how innovation works in the public sector, particularly at the statelevel. While a private sector chief information officer (CIO) may have considerably more latitude to enact innovation, such latitude rarely exists in the public sector where governors and elected legislators control the budget and outline strategic priorities for agencies. Further, it is not clear what would prompt one state to engage in innovation while another state would not. Finally, it is not clear what is necessary for successful innovation or even the relationship between innovation and positive organizational outcomes. In short, research is needed to understand innovation in the public sector and our research specifically focuses on the state-level.

\section{Public Sector Innovation Ecosystem}

\subsection{Public Sector IT Governance}

The focus on governance by practitioners and scholars is easily understandable. Research has consistently shown a strong link between IT governance and positive outcomes and firms with effective governance can expect to receive up to a $40 \%$ greater return on investment in IS and this is commonly attributed to achieving better IS-business alignment [3-5]. IT governance is not concerned with the location of the IT resources themselves but rather the "location distribution and pattern of managerial responsibilities and control that ultimately affect how IT resources are applied and then implemented" [6, p. 1].

IT governance refers to "...the organizational capacity exercised by the Board, Executive 
Management and IT management to control the formulation and implementation of IT strategy and in this way ensure the fusion of business and IT" [7] and "...consists of the leadership and organizational structures and processes that ensure that the organization's IT sustains and extends the organization's strategy and objectives" [8].

For decades it has been fashionable to assert that the public sector was merely a poorly performing cousin to the private sector and, to operate better, government simply needed to adopt private sector practices. For example, the Clinger-Cohen Act (CCA) was adopted by the federal government in 1996 to establish the role of the CIO within government and to task the CIO to implement specific IT-related actions in government and much of the focus was on porting private sector practices to the public sector [9]. Although only required for federal government agencies, state governments quickly adopted the principles of the CCA and also appointed CIOs with similar responsibilities [10]. While there are many IT management issues that are similar between the public and private sectors, there are some - such as linking IT planning and budgeting and technology transfer - that are unique to the public sector [11].

Another critical way in which public sector and private sectors differ is the nature of governance and oversight [12]. The public sector does not have a Board of Directors and elected officials are usually chosen due to their position on issues and seldom agree on an overriding goal akin to profit maximization. While elected officials can appoint key members of their staff, these appointments are still subject to scrutiny and in some cases can even be blocked by others in government. Also, public sector CIOs have to work within a structure that is seldom easy to change due to the history of legislation and mandates that influences the current posture, processes, and focus of the organization [13].

\subsection{Innovation Ecosystem}

Researchers define innovation as the generation and adoption of new ideas or behaviors [14] and these ideas may relate to a product, service or new technology. Innovation generation is the process that results in the identification of a product, service or technology that is new to the organization [15] and innovation adoption is its assimilation into the organization [14]. Given that organizations are presumed to adopt an innovation to maintain or improve organizational performance, our focus is on the innovation adoption. [16].
At present, the scant public sector research on innovation has suffered from a faulty belief that all types of innovation are conceptually and operationally similar and have the same antecedents and consequences [16]. Moving past this belief, we explore the innovation ecosystem, differentiate the types of innovation and the aspects of the ecosystem that lead to innovation, and study the impact of each type of innovation on organization level outcomes.

We adapt an ecological framework recommended by Costello et al. [17], which is based on the belief that open innovation (involving many organizations) has far surpassed closed innovation [18], particularly in the public sector. We made modifications to this ecological framework to fit the public sector but remain thematically consistent. For IT innovation, the primary organism of interest is the CIO since the CIO is primarily responsible for setting the IT strategic direction within the public sector [19]. Thus, with an ecological orientation, we look at the CIO and the CIO's interactions with the environment and other collaborators within the ecosystem. Specifically, we examine the characteristics of the CIO (personal dimension), the relationship of the CIO to the governor (interpersonal dimension), the structure (organizational dimension) that surrounds the CIO, and the environment within the state that the CIO operates (socio-economic dimension).

CIO Characteristics. While many characteristics may be influential, we focus on tenure as a key discriminator. Tenure can be measured in a variety of ways, including in a position, in an organization and within a discipline but results often overlap [20]. In the public sector, longer tenures are often seen and commonly attributed to an individual having a public service motivation and a longer tenure for the public sector CIO enables the CIO to build their networks, win credibility among peers and learn how to deal with shifting political cycles [21].

Relational. The relationship between the CIO and governor is of critical importance. Literature suggests higher levels of strategic alignment and performance occur when the CIO and the other members of the top management team have a shared language and domain knowledge [22]. Research in the public sector has shown that the most effective CIOs are ones that are closely aligned with the business area to develop that common understanding [23].

Structural. Structural considerations are heavily governance based [24] and are made more complex in the public sector where IT spending accountability relationship spread more broadly than the private sector [12]. In general, IT governance is believed to be more effective when the legislative branch is involved in controlling and monitoring IT [25]. A 
second structural factor, outsourcing, has been tied to open innovation and is an important aspect of technology strategy and implementation in the public sector, however, the level of outsourcing is not consistent across states [26]. A third structural factor is the tenure point for the incumbent governor, as a salient dimension of innovation.

Environmental. Environmental characteristics can shape an information system's ability to provide positive organizational outcomes. For example, the availability of sufficient and talented human resources, government regulations, the strength of the infrastructure and the other organizational climate factors can profound impact technology development, deployment and effectiveness [27]. Similarly, federal incentives can speed the diffusion of an innovation [28]. Innovation is often an organization's response to changing environment conditions [29] and this suggests that states may also adopt an innovation in response to the economic and education level of its citizens.

\section{Methodology}

\subsection{Qualitative Comparative Analysis}

In taking an ecological perspective, there should be an expectation of causal complexity and, therefore, adoption of methods designed to tease apart the phenomenon of interest. We adopt a settheoretic approach to investigating the phenomenon, as this approach identifies common relationships between configurations of multiple causal conditions and a set of outcomes [30]. Causal conditions are defined as "an aspect of a case that is relevant in some way to the researcher's account or explanation of some outcome” [30, p. 18]. Set-theoretic methods embrace causal complexity by allowing for combinations of components to lead to an outcome rather than a single factor and that the same antecedent can positively or negatively contribute to outcomes in different combinations [31]. Additionally, set-theoretic methods allow for equifinality - that there may be many equally valid paths to the same outcome [32]. Finally, set-theoretic methods are oriented to determining whether a condition or set of conditions are necessary - the condition or set of conditions is always present when the outcome occurs - and/or sufficient - the outcome always occurs when the condition or set of conditions is present [33]. A Boolean algebra-based set-theoretic approach can be used to capture both the causal complexity and equifinality components of configurational relationships in a parsimonious form [34].
One particular method within the family of settheoretic approaches for operationalizing and testing configuration theories is through Qualitative Comparative Analysis (QCA), which combines qualitative (case-based) and quantitative (variableoriented) techniques [35]. A specific form of QCA where the values of the conditions are binary is called crisp set QCA (csQCA), where values for each condition are set to 0 or 1 to denote whether an element is present or absent, ascribed a value of high or low, or is naturally dichotomized variables (male/female) [33]. QCA is ideal when working with an intermediate number of cases (generally defined as 30-50), although there is no procedural limit to greater numbers of cases being used [35]. While csQCA can be used to evaluate monocausal arguments [36], it finds its true strength in evaluating situations of causal complexity [35].

\subsection{Data/Operationalization}

Data for our outcomes were collected from several sources including the 2004 Compendium of the Survey of Digital Government in the States from the National Association of State CIOs (NASCIO) for the level of innovation and the 2005 Government Performance Project (GPP) from the Pew Charitable Trusts for the performance of the state.

NASCIO is an organization of state-level CIOs and senior IT executives from all 50 states plus six territories and the District of Columbia. Its members are drawn from the three branches of government and have state-level responsibility for information management. In the early 2000s, NASCIO produced a series of surveys entitled the "Compendium of Digital Governance in the States" to capture the level of IT activity at the state-level. The 2004 survey included responses for 42 states plus the District of Columbia accounting for $86 \%$ of the US population Data were collected between October 2002 and September 2003, grouped into 40 questions of 449 individual data elements. NASCIO compendium data has been used over 500 times in scholarly research including numerous times in top public administration journals.

The Pew Charitable Trusts have as a goal to serve the public interest by improving public policy. One mechanism to do so is the Governance Performance Project (GPP) which was a 14 year effort ending in 2010 to provide data to state governments in order to improve their management and goal achievement. Since 1996, this effort has been coordinated through The Maxwell School at Syracuse University and run with leading academics and practitioners. In 2005, as part of the "Grading the States" Report, each state 
was given an overall grade along with a grade for money, people, infrastructure and information. Pew GPP data has been used in over 2000 scholarly journals.

We acknowledge that secondary data is not always a perfect fit but believe that, in this case, the richness and consistency of the data overwhelms any potential issues. Consider this: our data comprise $84 \%$ of the states in the US and it would be virtually impossible to gather a similar percentage of companies in any single industry using identical data fields across all companies. As such, the public sector offers a scholarly laboratory that is unmatched in private industry.

We also acknowledge that our innovation and ecosystem data is from 2004 and that concerns may arise about the age of the data. We note that the concept of innovation is enduring and not tied to a particular epoch. Since we are studying the process of innovation rather than the individual innovations themselves, the richness and completeness of the data source - which was discontinued in 2005 - allow it to remain relevant in our study's context. While we acknowledge that some specific differences in individual states may occur between the time the data were collected and the present day, the data themselves do not impact on our formulation of the model or the interpretation of the results.

\subsubsection{Innovation Ecosystem}

We used multiple indicators for these constructs. This allows us to better see the richness in the analysis and ultimately allows us to create a more rich research agenda.

Personal Characteristics. We used the information from the 2004 Compendium to capture the incumbent $\mathrm{CIO}$ and Governor and then used LinkedIn, the State website and press releases to identify information on the incumbents: (1) CIO tenure within the state and (2) CIO tenure in the CIO position.

Structural Characteristics. We operationalized this construct from the 2004 Compendium to understand the structure that surrounds the CIO including: (1) Percentage of IT departmental staffing that is employees versus contractors, (2) proportion of outsourcing of IT functions, (3) the CIO's role on the IT Steering Committee, (4) if there is a legislative committee that oversees IT-related issues and (5) the length of the incumbent Governor's tenure.

Relational Characteristics. This construct looks at the power relationship that exists between the CIO and the governor and includes: (1) whether executive or legislative branch appoints the CIO and (2) if the
CIO was appointed during the incumbent Governor's mandate.

Environmental Characteristics. This construct examines the state environment that surrounds the CIO and includes: (1) the percentage of citizens with a bachelor's degree within the state, (2) the average income within the state, and (3) the overall population of the state. All of this information is publicly available and there was sufficient variation to make comparisons meaningful.

\subsubsection{Outcomes}

Innovation Level. The 2004 NASCIO Compendium identifies the level of investment (High/Medium/Low) in key innovative technologies (at that time) within each state including investment in dot-gov initiatives, customer relationship management, digital signatures, e-procurement, knowledge management, virtual private network and state websites in 2002/2003. In 2002/2003, these were innovative technologies and states had great disparity in their spending for each innovative technology. For example, in early 2004, egovernment initiatives (CRM, ERP, digital signatures and e-procurement) were just emerging and spending on e-government initiatives were projected to grow.

State-Level Performance. This data was from the 2005 Pew Charitable Trust and reflects the aggregate and individual performance of the state on the dimensions of use of information, infrastructure, people, and money. We felt it was appropriate to lag the assessment of the effectiveness of the innovation of the state with the implementation of the innovation and thus used the 2005 Pew report. We made this decision based on a belief that the benefits of the innovation would not be felt immediately but would begin and strengthen over time. Further, we do not believe that the innovation would be fully in place at the beginning of the year but would gradually be put in place throughout the course of the year. By using a one year lag, we are able to better see the impact of the innovation on state performance.

\section{Results}

\subsection{PCA - Innovation Ecosystem}

The 12 indicators from the four construct groups - personal, structural, relational and environmental provided substantial raw data to understand the CIO's environment. A Principal Components Analysis (PCA) was conducted to identify if there were common factors that could be applied. The subject- 
to-item ratio was between $5: 1$ and $10: 1$, which is an average ratio based on current practice [37]. The lower $\mathrm{n}$ was balanced by having high communalities (ranging from 0.715 to 0.947 ) which improved the fidelity of the results [38]. Barlett's test of sphericity identified at $\mathrm{p}>0.01$ that the items are not orthogonal and could therefore be reduced into factors. Three indicators with significant cross-loadings were dropped until nine remained. A scree test was used to identify an inflection point and thus determine the number of factors; this was done as the heuristic of retaining all factors with eigenvalues greater than 1.0 has been defined as the least accurate method of determining the number of factors to retain [39]. Rotation was orthogonal (varimax) as theoretically the factors were expected to be independent. As Nunnally [40] notes that 0.70 is a recommended benchmark for established measures, for an initial development with all loading above 0.80 and no cross-loadings above 0.30 , these are very consistent factors. Five components emerged from the analysis, explaining $83.8 \%$ of variance in the sample. Our interpretation of our public sector factors follows Table 1.

\begin{tabular}{|c|c|c|c|c|c|}
\hline & \multicolumn{5}{|c|}{ Component } \\
\hline & 1 & 2 & 3 & 4 & 5 \\
\hline $\begin{array}{l}\text { CIO Tenure in } \\
\text { State }\end{array}$ & .958 & -.004 & .053 & -.003 & -.049 \\
\hline $\begin{array}{l}\text { CIO Tenure as } \\
\text { CIO }\end{array}$ & .936 & -.079 & -.042 & .147 & .032 \\
\hline $\begin{array}{l}\text { State Education } \\
\text { Level }\end{array}$ & -.094 & .927 & -.011 & -.034 & .018 \\
\hline $\begin{array}{l}\text { State Average } \\
\text { Income }\end{array}$ & .018 & 899 & .105 & -.033 & -.023 \\
\hline $\begin{array}{l}\text { CIO Appointed by } \\
\text { Incumbent }\end{array}$ & -.256 & .026 & .834 & -.105 & .262 \\
\hline $\begin{array}{l}\text { Executive } \\
\text { Appoints CIO }\end{array}$ & .276 & .083 & .821 & .214 & -.139 \\
\hline $\begin{array}{l}\text { Proportion of IT } \\
\text { Outsourcing }\end{array}$ & -.141 & -.149 & -.087 & -.798 & .255 \\
\hline Governor Tenure & .003 & -.274 & .003 & .752 & .286 \\
\hline $\begin{array}{l}\text { Legislative IT } \\
\text { Oversight }\end{array}$ & .000 & .012 & .075 & -.003 & .938 \\
\hline
\end{tabular}

Table 1 - PCA for Antecedents to Innovation

Component 1. CIO tenure captures the longevity of the CIO within the position and within the state. It is not surprising that both types of tenure load together as researchers have repeatedly highlighted the strong connection between different types of tenure often co-vary and can be conceptually nested [20].
Component 2. State attainment reflects a clear delineation between have and have-not states in terms of income and education level within the state. It is not surprising that these items load together and provide support for the environmental dimension of the ecological perspective, particularly for public sector research.

Component 3. Relational characteristics reflects the closeness of the relationship between the CIO and the Governor, as indicated by whether the CIO was appointed within the mandate of the incumbent Governor and if it is the executive or legislative branch that makes the appointment. Where the CIO is appointed directly by the sitting Governor, the CIO can be seen to be closer and therefore more directly responsive and responsible to the Governor in meeting his or her mandate for innovation. The importance of this relationship is commonly seen in private sector organizations [22] but is less frequently studied in the public sector.

Component 4. Cost containment orientation captures the concept that new Governors tend to make sweeping changes and one of the most common cost containment initiatives is to move from internal to external provision of IT services [41]. Noting that the two items are negatively correlated, we see that as Governor's tenure increases, propensity to outsource decreases, signifying a change from cost containment to service effectiveness. This aligns with our belief that newly elected governors have a great deal more latitude to take bold actions while later term governors are often hamstrung.

Component 5. Structural characteristics reflects whether the CIO exists in an environment with a high level of legislative oversight on the CIO. This factor would seem to fly counter to the philosophy that a high level of IT expertise is necessary to successfully oversee IT functions (including IT-enabled innovation) but conversely support the requirement for strong IT governance, which is defined here as having both legislative chambers establishing IT steering committees to whom the CIO reports.

\subsection{PCA - IT Innovation Types}

There were 10 technology innovations in the 2004 Compendium. Using the same technique as for the antecedent components, a PCA was conducted to identify if there were common innovation factors that could be applied. Four components emerged and were maintained while the three items that showed significant cross-loadings were dropped. Table 2 demonstrates that all of the loading were above 0.70 and no cross-loadings were above 0.40 . 


\begin{tabular}{|l|c|c|c|c|}
\hline \multirow{2}{*}{} & \multicolumn{4}{|c|}{ Component } \\
\cline { 2 - 5 } & 1 & 2 & 3 & \multicolumn{1}{|c|}{4} \\
\hline E-Sign Implementation & .878 & .067 & .188 & .020 \\
Electronic Procurement & .810 & .167 & -.220 & .221 \\
Enterprise Resource & .715 & .322 & .229 & -.216 \\
Planning & & & & \\
IT Office Customer & .178 & .903 & .012 & .029 \\
Billing System & & & & \\
Cust Relationship & .159 & .867 & .159 & .115 \\
Management & & & & \\
VPNs/Collaborative & .091 & .125 & .941 & .126 \\
Tools & & & & \\
Dot.Gov Naming & .036 & .104 & .123 & .959 \\
\hline
\end{tabular}

Table 2 - PCA for Public Sector IT Innovation

Four components emerged from the analysis, explaining $83.5 \%$ of variance in the sample. Because our interest is on type of innovation rather than on a specific innovation, we interpret these innovation factors from a type perspective.

Component 1: Administrative innovation focuses on projects to improve government processes, including electronic sign implementation, electronic procurement introduction and enterprise resource planning. These are internally focused projects that seek to redesign state agency processes and information usage through IT.

Component 2: Public service delivery innovation focuses on projects to improve service to customers, including IT office customer billing and customer relationship mgmt. These externally focused projects are designed to improve processes surrounding handling of customers and their information.

Component 3: Human resources innovation focuses on providing the underlying connectivity and the overarching collaborative tools to support State employee activities. As such they are internally focused and also are much more about automation than the changing underlying business processes.

Component 4: Citizen engagement innovation focuses on presenting a common State-level face to the population of citizens by bringing all agencies onto the dot-gov framework. These are externally facing and are also largely automation-focused.

\subsection{Configurational Analysis}

Once a correlation between some of the factors and outcomes had been established, the factors were dichotomized in order to conduct the csQCA. This was done by assigning those cases above the mean as high and those below the mean as low for each of the five constructed factors. While it is preferred to find theoretical divisions between high and low scores [34] given the components were generated through PCA through combination of underlying factors, using the mean was the best method available. This created 32 (i.e. 25) possible combinations of the factors for the analysis. In crisp set analysis, there are four different possible outcomes: a consistent set of negative results; a consistent set of positive results; a set of contradictory configurations where the same combination of conditions leading to both positive and negative outcomes; and a non-observed, logical remainder which is devoid of cases due to limited diversity from a limited population size.

The csQCA was conducted to determine the best solutions using fs/QCA 2.5 [42]. As part of the analysis, three solutions are presented parsimonious, intermediate and complex [43]. Complex solutions are exhaustive, listing every combination; intermediate solutions include the addition of a redundant, unobserved condition to simplify the solution; and parsimonious solutions include both the addition and removal of redundant and unobserved condition [30]. Core configurations are identified by their appearance in both intermediate and parsimonious solutions and peripheral in just the intermediate solution [43]. The notation used is adopted from previous studies [43, 45] where black circles ( $)$ indicate the necessary presence of a condition and crossed-out circles $(\theta)$ indicate its necessary absence. Where present, a large circle (O) indicates a core condition and a small circle (•) indicates a peripheral condition. The absence of a circle indicates that presence or absence of the condition does not impact on the outcome (i.e. the same result occurs whether there condition is present or absent). To provide optimal presentation clarity, solutions are grouped by core conditions (i.e. $\mathrm{A}, \mathrm{B}$ and $\mathrm{C}$ have the same core conditions). Findings are presented for both high and low levels of innovation.

We analyzed each of the four different forms of IT-based innovation and came to very similar results (see Table 3): a long-serving CIO (CIO characteristic) who was appointed by and has a strong relationship with the sitting Governor (relational), working in a have-not state (environmental) with a cost-containment orientation (structural). The common core conditions here were a combination of weak environmental and positive relational characteristics.

Similarly, we analyzed each of the four innovation types individually and found commonalities (see Table 4): a sometimes shortserving CIO (CIO characteristic) who was not 
appointed by and has a weak relationship with the sitting Governor (relational), working in a have-not state (environmental) with a sometime costcontainment orientation (structural) and under weak legislative oversight (structural). The core conditions were a combination of weak environmental, relational and structural components.

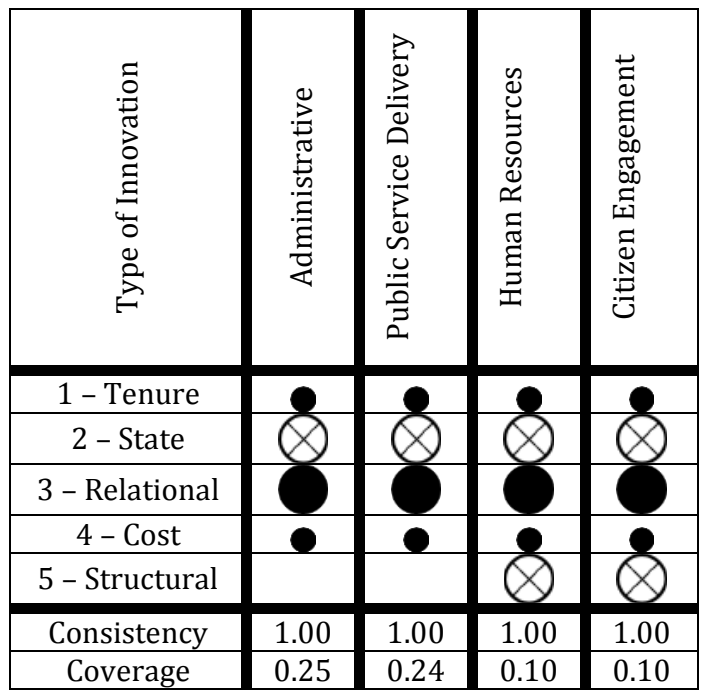

Table 3 - High Innovation Configurations

\begin{tabular}{|c|c|c|c|c|c|c|}
\hline $\begin{array}{l}\text { Type of } \\
\text { Innovation }\end{array}$ & & & & & 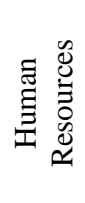 & 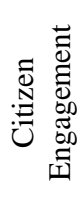 \\
\hline Configuration & $1 \mathrm{~A}$ & 1B & $1 \mathrm{~A}$ & 1B & 1 & 1 \\
\hline $1-$ Tenure & (8) & & & & & \\
\hline 2 -State & $\theta$ & $Q$ & & 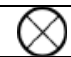 & 8 & 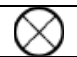 \\
\hline 3 - Relational & $\theta$ & 8 & & 8 & & \\
\hline $4-$ Cost & & 8 & & 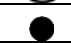 & & 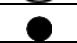 \\
\hline 5 - Structural & $Q$ & $Q$ & $Q$ & $Q$ & $Q$ & \\
\hline Consistency & 0.86 & 1.00 & 0.86 & 1.00 & 1.00 & 1.00 \\
\hline Raw coverage & 0.30 & 0.15 & 0.32 & 0.26 & 0.26 & 0.32 \\
\hline $\begin{array}{c}\text { Unique } \\
\text { coverage }\end{array}$ & 0.15 & 0.10 & 0.16 & 0.11 & & \\
\hline
\end{tabular}

Table 4 - Low Innovation Configurations

It is notable that poor state attainment is a common component throughout the analysis, meaning that we were only able to discern configurations for high and low performance for have-not states. For states with higher educational and income levels, there may be different antecedents that merit further investigation. Similarly, both cost containment and weaker legislative oversight made appearances in both high and low performing configurations, suggesting that they may be factors associate with have-not states. In contrast, the main differentiators appeared to be the tenure of the CIO and his or her relationship with the Governor, suggesting that one of the critical tasks for a newly elected official is to select a CIO and then work with him or her to implement the Governor's vision to achieve innovation over the duration of the Governor's mandate.

\begin{tabular}{|c|c|c|}
\hline Type of Innovation & High & Low \\
\hline 1 - Administrative & & Q \\
\hline 2 - Public service delivery & & \\
\hline 3 - Human resources & & $\otimes$ \\
\hline 4 - Citizen engagement & & \\
\hline Consistency & 0.786 & 0.800 \\
\hline Coverage & 0.579 & 0.571 \\
\hline
\end{tabular}

Table 5 - Organizational Performance

There was a single dominant high performance configuration based upon investment in all four categories of innovation (see Table 5). However, it is notable that the core conditions for this configuration are public service delivery and citizen engagement innovation. Similarly, the single dominant negative configuration showed a lack of administrative, public service delivery and human resources innovation, with the latter being the core condition.

\section{Interpretation}

One striking result from our analysis is the frequency in which negative state attainment appears as a predictor of both positive and negative innovation, but in different configurations. That is, states are far more likely to engage in innovation when state attainment -- low income and low education -- are present, but only in the presence of other conditions such as long-tenure CIOs and relational and structural characteristics. Given that private sector organizations innovate in order to gain a competitive advantage, our results show that states innovate to address systemic state-wide issues and this has support in literature [45]. While innovation in the private sector may be an offensive strategy in order to move past the competition, clearly it is a reactive strategy in the public sector to overcome problems. As such, innovation appears to provide a "bridge" over the issues with the state. As a result, we would expect that low statewide attainment would be a catalyst to get the governor, CIO and state legislature to consider innovation. Equally, however, 
we can also observe that this effort towards innovation is not uniformly successful.

Our data show that low state attainment can spur the involvement of the governor, legislature and CIO in order to try to overcome the systemic problems within the state, but only when they work together. Indeed, a distinguishing feature of states with significant usage of information technology was a governor and legislature that were committed to its use [46]. Rather than simply doing innovation for the sake of innovation, this suggests that all of the related actors are trying to implement innovation to address serious state-wide problem.

We suspect that the governor's involvement is to provide political support to spend the money to foster innovation. Since the governor provides his/her proposed budget at the start of each budget cycle, the governor can make it clear what his/her priorities are for spending. By providing money for implementation, the governor can clearly indicate the importance of innovation and this provides a great deal of political coverage for the CIO to undertake technology-based innovation.

The role of the legislature can figure in innovation but only in externally facing innovation. Since most legislators lack technology expertise and only get involved with externally facing projects, we surmise that their role is less about control and is more about public interest. Additionally, we argue that the control role that is traditionally played by a private sector Board of Directors simply does not fit with the open nature of the public sector. Every state has a purchasing agency, which is responsible for control over contracting and an audit agency that is responsible for control during and after the project. Thus, it is simply unnecessary for the legislature to provide control since it is already being performed elsewhere in government.

Finally, the tenure of the CIO is key for successful innovation and longer serving CIOs are more likely to be innovative. A far cry from transplanted CIOs from the private sector, longtenured public sector CIOs have likely built up a productive working relationship with the legislature and the governor, and, in the process, have built a strong sense of trust. We suggest that the CIO is likely operating as the "champion" for the innovation while the governor acts in the role of the "sponsor" [47]. Thus, the CIO serves to inspire the change, the governor as the sponsor provides the funding and authority to actually implement the innovation [47].

The CIO's tenure also likely plays a role in how the governance relationship works with the legislature. Contrary to the belief that the politicians and legislature create static governance structure to constrain behaviors of managers, evidence suggests that governance structure is the result of a reciprocal structure that develops between the manager (CIO) and the legislature/governor [48]. Based on this, we suggest that a new CIO would be subjected to the traditional (top-down) type of governance but, as the CIO's tenure increases, the governance structure would evolve based on the nature of the relationship. In short, far from a rogue CIO implementing innovation, the reality is that innovation reflects a strong team effort with the governor, legislature and CIO working collaboratively.

\section{Concluding Comments}

This research makes several contributions. First, it highlights that innovation in the public sector differs in key ways from innovation in the private sector and this prevents an easy transfer of scholarship and practice between domains. While private sector innovation research can inform research in the public sector, the domains are sufficiently dissimilar to require additional study.

Second, this research confirms a key tenant of IS leadership: relationships are key. The CIO's relationship with the governor and the state legislature are key to successful innovation implementation. Further, this relationship appears to increase with time and so tenure in the position yields key dividends.

Third, while innovation leads to immediate improvements in organizational performance, these improvements could be fleeting. This suggests that a state needs to continuously innovate in order to perform, with a parallel to the difficulty in maintaining sustainable competitive advantage through IT-enabled innovation in the private sector.

As with all research studies, the current study has certain limitations. First, we note that the data was collected from secondary sources. While there is every reason to accept that the data within the data set is accurate, since there is degree of quality control required for each state of the state databases, there is always the possibility that errors exist. However, given the number of hours that each state asserted in collecting this data, we believe that the chance of errors is limited. Second, we do not assert that the variables highlighted in the current study are the only elements that could potentially influence the creation of innovation nor are these the only types of innovations that exist. Third, our configurational results only focused on have-not states as these were the only consistent relationships that could be identified. There remain opportunities to explore how 
high attainment states use innovation to achieve their goals.

Good government is essential for a smoothly functioning society and the social and physical welfare of its citizens. During the last several decades, technology has contributed in large and small ways towards good government. However, in the era of shrinking budgets, lack of economic parity and increased social demands, the demand for good government is expected to grow and the role of technology in addressing these issues is substantial. By focusing on IT-enabled innovation, the IS community can contribute to the betterment of society.

\section{References}

[1] Collins, H. "Enterprise Resource Planning Aids Streamlining, Transparency Efforts," Government Technology, 29 April 2011.

[2] McCullen, K. "North Carolina's New Chief Information Officer Discusses Recent State Audit and the Challenges It Presents," UNC TV, 25 January 2013.

[3] Benz, M., and Frey, B.S., "Corporate Goverance: What Can We Learn from Public Governance", Academy of Management Review, 32(1), 2007, pp. 92-104.

[4] Campbell, J. L., McDonald, C. J., and Sethibe, T., "Public and Private Sector IT Governance: Identifying Contextual Differences," Australasian Journal of Information Systems, 16(2), 2010, pp. 1-18.

[5] Bozeman, B., and Bretschneider, S., "Public Management Information Systems: Theory and Prescription," Public Administration Review, 46(6), 1986, pp. 475-487.

[6] Rocheleau, B., and Wu, L., "Public Versus Private Information Systems: Do They Differ in Important Ways? A Review and Empirical Test," The American Review of Public Administration, 32(4), 2002, pp. 379-397.

[7] Weill, P., and Ross, J.W., IT Governance: How Top Performers Manage IT Decision Rights for Superior Results, Harvard Business School Press, Boston, MA, 2004.

[8] Weill, P., "Don't Just Lead, Govern: How TopPerforming Firms Govern IT", MIS Quarterly Executive, 3(1), 2004, pp. 1-17.

[9] Liu, S., and Hwang, J. "Challenges to Transforming within the Us Government,” IT Professional, 5(3), 2003, pp. 10-15.

[10] Rocheleau, B., and Wu, L. "Private Versus Private Information Systems: Do They Differ in Important Ways? A Review and Empirical Test," The American Review of Public Administration, 32(4), 2002, pp. 379-397.

[11] Caudle, S. L., Gorr, W. L., and Newcomer, K. E. "Key Information Systems Management Issues for the Public Sector,” MIS Quarterly, 15(2), 1991, pp. 171-189.

[12] Campbell, J. L., McDonald, C. J., and Sethibe, T. "Public and Private Sector IT Governance: Identifying Contextual Differences," Australasian Journal of Information Systems, 16(2), 2010, pp. 5-18 .
[13] Rainey, H. G., and Bozeman, B. "Comparing Public and Private Organizations: Empirical Research and the Power of a Priori," Journal of Public Administrative Research Theory (10:2), 2000, pp. 447-469.

[14] Damanpour, F., and Wischnevsky, J. D. "Research on Organizational Innovations: Distinguishing InnovationGenerating from Innovation-Adopting Organizations," Journal of Engineering and Technology Management, 23(4), 2006, pp. 269-291.

[15] Daft, R.. L. "A Dual-Core Model of Organizational Innovation,” Academy of Management Journal, 21(2), 1978, pp. 193-210.

[16] Walker, R. M. “An Emprical Evaluation of Innovation Types and Organizational and Environmental Characteristics: Towards a Configuration Framework," Journal of Public Administrative Research and Theory, 18(4), 2007, pp. 591-615.

[17] Costello, G. J., Donnellan, B., and Curley, M. “A Theoretical Framework to Develop a Research Agenda for Information Systems Innovation," Communications of the Association for Information Systems (33:26), 2013..

[18] Chesbrough, H. W. Open Business Models: How to Thrive in the New Innovation Landscape. Harvard Business School Press, 2013.

[19] Smaltz, D. H., Sambamurthy, V., and Agarwal, R. "The Antecedents of CIO Role Effectiveness in Organizations: An Empirical Study in the Healthcare Sector," IEEE Transactions on Engineering Management, 53(2), 2006, pp. 207-222.

[20] Finkelstein, S., and Hambrick, D. C. Strategic Leadership : Top Executives and Their Effects on Organizations. Minneapolis/St. Paul: West Pub. Co, 1996.

[21] Feiock, R., and Stream, C. "Explaining the Tenure of Local Government Managers," Journal of Public Administrative Research and Theory, 8(1), 1998, pp. 117130.

[22] Preston, D. S., and Karahanna, E. "Antecedents of IS Strategic Alignment: A Nomological Network,” Information Systems Research, 20(2), 2009, pp. 159-179.

[23] Dawson, G. S., and Watson, R. T. "Uncovering and Testing Archetypes of Effective Public Sector CIOs," ACM Transactions of Management Information Systems, 2(1), 2011, p. 5.

[24] Wise, C. R. "Public Service Configurations and Public Organizations: Public Organization Design in the PostPrivatization Era," Public Administration Review, 50(2), 1990, pp. 141-155.

[25] Pang, M.-S. "IT Governance and Business Value in the Public Sector Operations-the Role of Elected Representatives in IT Governance and Its Impact on IT Value in US State Governments," Decision Support Systems, (59), 2014, pp. 274-285.

[26] Ya Ni, A., and Bretschneider, S.. "The Decision to Contract Out: A Study of Contracting for E-Government Services in State Governments," Public Administration Review, 67(3), 2007, pp. 531-544.

[27] Melville, N., Kraemer, K., and Gurbaxani, V. "Review: Information Technology and Organizational Performance: An Integrative Model of IT Business Value," MIS Quarterly, 28(2),.2004, pp. 283-322. 
[28] Welch, S., and Thompson, K. "The Impact of Federal Incentives on State Policy Innovation," American Journal of Political Science, 24(4), 1980, pp. 715-729.

[29] Kearney, R. C., Feldman, B. M., and Scavo, P. F. "Reinventing Government: City Manager Attitudes and Actions," Public Administration Review, 60(6), 2000, pp. 535-547.

[30] Ragin, C. C. Redesigning Social Inquiry: Fuzzy Sets and Beyond. Chicago: University of Chicago Press, 2008.

[31] Ragin, C. C. The Comparative Method: Moving Beyond Qualitative and Quantitative Strategies. Oakland, CA: University of California Press, 1987.

[32] Meyer, A., Tsui, A. S., and Hinings, C. R. "Configurational Approaches to Organizational Analyses," Academy of Management Journal, 36(6), 1993, pp. 11751195.

[33] Rihoux, B., and De Meur, G. "Crisp-Set Qualitative Comparative Analyses (Csqca)," in Configurational Comparative Methods: Qualitative Comparative Analysis (QCA) and Related Techniques, B. Rihous and C.C. Ragin (eds.). Thousand Oaks, CA: SAGE Publications, 2009, pp. 33-68.

[34] Fiss, P. C. "A Set-Theoretic Approach to Organizational Configurations," Academy of Management Review, 32(4), 2007, pp. 1180-1198.

[35] Berg-Scholsser, D. and De Meur, G. "Qualitative Comparative Analysis (QCA) as an Approach," in Configurational Comparative Methods: Qualitative Comparative Analysis (QCA) and Related Techniques, B. Rihoux and C.C. Ragin (eds.). Thousand Oaks, CA: SAGE Publications, 2009, pp. 1-18.

[36] Rivard, S., and Lapointe, L. "Responses to User Resistence: Nature and Effects," MIS Quarterly, 36(3), 2012, pp. 897-920.

[37] Costello, A. B., and Osborne, J. W. "Best Practices in Exploratory Factor Analysis: Four Recommendations for Getting the Most from Your Analysis," Practical Assessment, Research \& Evaluation, 10(7), 2005, pp. 1-9.

[38] Velicer, W. F., and Fava, J. L. "Effects of Variable and Subject Sampling on Factor Pattern Recovery," Psychological Methods, 3(2), 1998, pp. 231-251.

39] Velicer, W. F., and Jackson, D. N. "Component Analysis Versus Common Factor Analysis-Some Further Observations," Multivariate Behavioral Research, 25(1), 1990, pp. 97-114.

[40] Nunnally, J. Psychometric Theory. New York: McGraw-Hill, 1967.

[41] Willcocks, L. P., and Lacity, M. C. Strategic Sourcing of Information Systems: Perspectives and Practices. Chichester, England, New York: Wiley, 1998.

[42] Ragin, C. C., and Davey, S. "fs/QCA." Irvine, CA: University of California, 2009..

[43] Fiss, P. C. "Building Better Causal Theories: A Fuzzy Set Approach to Typologies in Organizational Research," Academy of Management Journal, 54(2),, 2009, pp. 393420.

[44] Ragin, C. C., and Fiss, P. C. "Net Effects Analysis Versus Configurational Analysis: An Empirical Demonstration," in Redesigning Social Inquiry: Fuzzy Sets and Beyond, C.C. Ragin (ed.). Chicago: University of Chicago Press, 2008, pp. 190-212.
[45] Damanpour, F., and Schneider, M. "Characteristics of Innovation and Innovation Adoption in Public Organizations: Assessing the Role of Managers," Journal of Public Administrative Research and Theory, 19(3), 2008, pp. 495-522.

[46] McNeal, R. S., Tolbert, C. J., Mossberger, K., and Dotterweich, L. J. "Innovating in Digital Government in the American States," Social Science Quarterly, 84(1), 2003, pp. 52-70.

[47] Beath, C. M. "Supporting the Information Technololgy Champion,” MIS Quarterly, 15(3), 1991, pp. 355-372.

[48] Feldman, M.S., and Khademian, A.M. "To Manage is to Govern," Public Administration Review, 62(5), 2002, pp. 541-554. 